\title{
Bax is downregulated in inflamed colonic mucosa of ulcerative colitis
}

\author{
M Iimura, T Nakamura, S Shinozaki, B Iizuka, Y Inoue, S Suzuki, N Hayashi
}

\begin{abstract}
Background and aims-One form of epithelial cell injury in inflamed colonic mucosa in ulcerative colitis (UC) is reported to involve apoptosis of these cells. Bcl-2 family proteins Bax and Bcl-2 are the major regulators of apoptosis. The aim of this study was to elucidate the involvement of the Bax/Bcl-2 system in induction of apoptosis of the inflamed colonic epithelium in UC.

Methods-Colonic epithelium was isolated from colonic biopsy specimens. Expression of CD95, Bax, Bcl-xL, and Bcl-2 proteins was determined by western blotting. Bax gene expression was assessed by both reverse transcription-polymerase chain reaction (RT-PCR) followed by Southern hybridisation and a real time PCR assay.

Results-Equal levels of expression of CD95, Bcl-xL, and Bcl-2 proteins were noted in normal and UC colonic epithelia. Equal levels of expression of Bax protein and mRNA were noted in epithelia of normal colon and inactive UC. Levels of expression of Bax protein and $\mathrm{mRNA}$ were markedly reduced in inflamed UC colonic epithelium.

Conclusions-Our study showed for the first time downregulation of $\mathrm{Bax}$ in inflamed colonic epithelium of UC. The Bax/Bcl-2 system did not seem to be involved in induction of apoptosis of epithelial cells in the inflamed colonic mucosa of UC.

(Gut 2000;47:228-235)
\end{abstract}

Keywords: ulcerative colitis; apoptosis; Bax; Bcl-2; Bcl-xL; CD95

Ulcerative colitis (UC) is characterised by chronic inflammation of the colonic mucosa. The exact pathogenic mechanism of UC is still unclear. Permeability of colonic mucosa is thought to be increased in inflammatory bowel disease (IBD) ${ }^{1-3} \mathrm{~A}$ breakdown of the epithelial barrier in UC may facilitate invasion of pathogenic microorganisms, potentially leading to chronic inflammation of the colonic mucosa. Several mechanisms have been proposed to explain epithelial damage in inflamed colonic mucosa, such as CD95-CD95L induced apoptosis of crypt epithelial cells. ${ }^{45}$ Other known inducers or mediators of apoptosis are the perforin-granzyme system,${ }^{6}$ tumour necrosis factor $\alpha(\mathrm{TNF}-\alpha),{ }^{7}$ and nitric oxide (NO). ${ }^{8}$ Recently, various cytokine receptors including interleukin (IL)-1 $\beta$, IL-6, TNF- $\alpha$, and granulocyte macrophage-colony stimulating factor have been identified on the surface of colonic epithelium. ${ }^{19}$ These new findings suggest that many factors could influence apoptosis of crypt epithelial cells in inflamed colonic mucosa in UC.

The Bcl-2 family of proteins are major regulators of the cell death programme. ${ }^{10} \mathrm{Bcl}-2$ and Bcl-xL can inhibit apoptosis induced by active caspases and promote cell survival. ${ }^{11-13}$ In contrast, the proapoptotic protein Bax homodimerises or heterodimerises with $\mathrm{Bcl}-2$ to counter its antiapoptotic effect. ${ }^{14}$ Bax induces apoptosis by acting on mitochondria and regulating caspase activity. ${ }^{15-17}$ Furthermore, the ratio of $\mathrm{Bcl}-2$ to Bax determines survival or death following apoptotic stimulation. ${ }^{14}$

In the normal colon of mice, Krajewski and colleagues $^{18}$ reported intense Bax immunostaining in surface epithelial cells compared with the bases of the colonic crypts, whereas Bcl-2 immunostaining was more prominent in epithelial cells located in the bases of the crypts. The reciprocal pattern of Bax and Bcl-2 expression in the colonic epithelium is consistent with the patterns of epithelial cell selfrenewal and death in the colon. ${ }^{19}$

In the inflamed colonic mucosa of UC, it is conceivable that mediators known to cause epithelial cell injury such as NO could damage the DNA of epithelial cells and then induce p53 expression. p53 upregulates Bax and downregulates Bcl-2. ${ }^{20}{ }^{21} \mathrm{p} 53$ induced apoptosis through regulation of the $\mathrm{Bax} / \mathrm{Bcl}-2$ system may be one form of epithelial cell injury in UC. However, little is known of the patterns of Bax and Bcl-2 expression in the colonic epithelium of UC.

In the present study, we investigated the role of the $\mathrm{Bax} / \mathrm{Bcl}-2$ system in induction of apoptosis of inflamed colonic epithelial cells. For this purpose, we determined expression of Bax, Bcl-2, CD95, and Bcl-xL in inflamed and non-inflamed colonic epithelia of UC and normal colonic epithelium.

\section{Patients and methods}

PATIENTS AND TISSUES

Colonic biopsy specimens were obtained by endoscopy from 20 patients with UC (in three patients with UC, colonic biopsy specimens were obtained at different times during the active and inactive phases of the disease) and

Abbreviations used in this paper: UC, ulcerative colitis; IBD, inflammatory bowel disease; NO, nitric oxide; TNF- $\alpha$, tumour necrosis factor $\alpha$; IL, interleukin; IFN- $\gamma$, interferon $\gamma$; SIN-1,

3-morpholinosydnonimine; RT-PCR, reverse transcription-polymerase chain reaction, Et-Br; ethidium bromide; mAb, monoclonal antibody, hr; human recombinant; GAPDH;

glyceraldehyde-3-phosphate dehydrogenase; PBS, phosphate buffered saline; BSA, bovine serum albumin; NF- $\kappa \mathrm{B}$, nuclear factor $\kappa \mathrm{B}$. 
10 normal controls (table 1 ). The diagnosis of UC was based on established endoscopic and histological criteria. ${ }^{22}$ Inactive UC represented cases with endoscopically healed areas and tissue specimens featuring crypt atrophy or distortion with no neutrophil infiltration. In contrast, active UC represented cases with endoscopically inflamed areas of low to moderate grade (increased granularity and friability of the mucosa) and areas of erosion or ulceration were excluded. Histological inflammatory activity was evaluated based on the degree of neutrophil infiltration according to Matts' grade $^{23}$ and grades 1 and 2 were classified as active in this study. We also examined biopsies of colonic epithelium obtained from patients with active Crohn's disease $(n=5)$, inactive Crohn's disease $(n=3)$, and ischaemic colitis $(n=2)$ for relative amounts of Bax gene transcripts. Informed consent was obtained from all patients and normal controls (patients with colorectal cancer and polyps) before biopsy. The study was approved by the Institutional Review Committee for Research on Human Subjects. Demographic features of the patients and history of drug therapy up to the time of colonoscopy are summarised in table 1 .

CELL LINE

The human colon cancer cell line (HT29) was obtained from the American Type Culture Collection (Rockville, Maryland, USA).

CYTOKINES AND REAGENTS

Recombinant human (rh) IL-1 $\beta$, rhIL-6, rh interferon $\gamma$ (rhIFN- $\gamma$ ), and rhTNF- $\alpha$ were purchased from BIOSOURCE (Camarillo, California, USA). rhIL-4 was purchased from PharMingen (San Diego, California, USA), and 3-morpholinosydnonimine (SIN-1) from Sigma (St Louis, Missouri, USA).

ISOLATION OF COLONIC CRYPT AND SURFACE EPITHELIUM

Colonic crypts and surface epithelia were isolated from colonic biopsy specimens in sheets consisting of both crypt and surface epithelium using the method described by Matsubara and colleagues $^{24}$ with minor modifications. Briefly, immediately after obtaining the colonic biopsy, the specimen was immersed in $10 \mathrm{ml}$ of calcium/magnesium free Hank's balanced salt solution (Life Technologies, Gaithersburg,

Table 1 Demographic features of participating patients

\begin{tabular}{llll}
\hline & \multicolumn{2}{l}{ Ulcerative colitis } & \\
\cline { 2 - 3 } & Active & Inactive & Control \\
\hline No of patients & 15 & 8 & 10 \\
Sex (male/female) & $8 / 7$ & $4 / 4$ & $7 / 3$ \\
Age (years) & & & \\
$\quad$ Range & $24-59$ & $26-59$ & $32-72$ \\
$\quad$ Mean & 39.3 & 38.6 & 56.4 \\
Disease duration (y) & & & \\
$\quad$ Range & $0.5-14$ & $1-19$ & \\
$\quad$ Mean & 6.9 & 8.2 & \\
Treatment & & & \\
$\quad$ Cyclosporin & 2 & 0 & \\
$\quad$ Steroids & 8 & 4 & \\
$\quad$ Sulphasalazine/5-ASA & 4 & 4 & \\
$\quad$ only & & & \\
$\quad$ No treatment & 3 & 0 & \\
\hline
\end{tabular}

Maryland, USA) containing $30 \mathrm{mM}$ EDTA and incubated at room temperature for 30 minutes. After incubation, the colonic crypts and surface epithelia were isolated mechanically using fine needles by microscopy. The isolated epithelium was allowed to stabilise in cold RPMI 1640 medium on ice and used to extract RNA and protein. That the isolated samples contained only crypt and surface epithelium was demonstrated morphologically using light microscopy, and by haematoxylin and eosin staining of histological sections.

\section{IMMUNOHISTOCHEMISTRY}

Biopsy specimens were partially fixed with $4 \%$ neutral formalin immediately after harvesting. Formalin fixed materials were embedded in paraffin using standard procedures. Deparaffinised and rehydrated sections were immersed in $0.01 \mathrm{M}$ citrate buffer $(\mathrm{pH} \mathrm{6.0)}$ ) and autoclaved at $121^{\circ} \mathrm{C}$ for 10 minutes for antigen retrieval of $\mathrm{Bax}$ and $\mathrm{Bcl}-2$ proteins. In the next step, sections were immersed in $0.3 \% \mathrm{H}_{2} \mathrm{O}_{2}$ in methanol and then preincubated with $0.5 \mu \mathrm{g} / \mathrm{ml}$ of normal rabbit IgG (for Bax staining) or normal mouse IgG (for Bcl-2 staining) in $1 \%$ bovine serum albumin (BSA)/phosphate buffered saline (PBS) for one hour. Sections were reacted with rabbit anti-Bax antibody (P-19) (1:200; Santa Cruz Biotechnology, Santa Cruz, California, USA) or mouse anti-Bcl-2 antibody (Bcl-2-100) (1:200; Santa Cruz Biotechnology) diluted with $1 \%$ BSA/ PBS overnight at $4^{\circ} \mathrm{C}$. After washing three times for 10 minutes each with $0.075 \%$ Brij $35 /$ PBS, the binding sites of the primary antibody were visualised using a biotinstreptavidin peroxidase system (Santa Cruz Biotechnology).

WESTERN BLOT ANALYSIS

Epithelial tissues isolated from normal and UC colonic mucosa were assayed for $\mathrm{Bax}, \mathrm{Bcl}-2$, Bcl-xL, CD95, and $\beta$-actin. The lysis buffer used to extract protein from colonic epithelium was $10 \mathrm{mM}$ PIPES (pH 6.8) supplemented with $100 \mathrm{mM} \mathrm{NaCl}, 5 \mathrm{mM} \mathrm{MgCl}, 300 \mathrm{mM}$ sucrose, $5 \mathrm{mM}$ EGTA, 1\% Triton X 100, $0.2 \mathrm{mM}$ sodium orthovanadate (Sigma), $0.2 \mathrm{mM}$ AEBSF (Calbiochem Co., La Jolla, California, USA), $1 \mu \mathrm{g} / \mathrm{ml}$ aprotinin (Calbiochem), $1 \mathrm{mM}$ benzamidine (Sigma), $10 \mu \mathrm{g} / \mathrm{ml}$ leupeptin (Calbiochem), and $10 \mu \mathrm{g} / \mathrm{ml}$ pepstatin (Calbiochem). Equal amounts of protein $(20 \mu \mathrm{g})$ from each epithelial or HT29 cell lysate were loaded onto $15 \%$ sodium dodecyl sulphate-polyacrylamide gels and electrophoresed. The separated proteins were then transferred to a polyvinylidene fluoride membrane (Immobilon-P; Millipore Corp., Bedford, Massachusetts, USA). For analysis of Bax expression, the membrane was stained with rabbit anti-Bax antibody (P-19; Santa Cruz Biotechnology). The same membrane used to analyse Bax expression was sequentially reprobed for analysis of $\mathrm{Bcl}-2$, $\beta$-actin, Bcl-xL, and CD95 expression in this order, according to the instructions provided by the manufacturer (ECL western blotting protocols; Amersham Life Science, Buckinghamshire, UK). Other primary antibodies used for western 
blot analysis included mouse anti-Bcl-2 antibody (Bcl-2-100; Santa Cruz Biotechnology), rabbit anti-Bcl-xL antibody (H-62; Santa Cruz Biotechnology), rabbit anti-CD95 antibody (C20-G; Santa Cruz Biotechnology), and goat anti- $\beta$-actin antibody (I-19; Santa Cruz Biotechnology). Primary antibodies were detected with donkey antirabbit IgG, sheep antimouse IgG, or donkey antigoat IgG linked to horseradish peroxidase and were developed by enhanced chemiluminescence western blot analysis (ECL western blotting system; Amersham).

\section{RT-PCR AND SOUTHERN HYBRIDISATION}

Total RNA was extracted from the isolated colonic epithelium as described previously. ${ }^{25}$ Reverse transcription (RT) of extracted RNA (500 ng) was performed using RNase $\mathrm{H}$-deficient reverse transcriptase (Superscript II, Life Technologies, Gaithersburg, Maryland, USA) and oligo(dT) primers (Life Technologies). Aliquots $(2 \mu \mathrm{l})$ of diluted RT reaction mixture $(40 \mu \mathrm{l})$ were used for PCR. The primer set used to amplify Bax was: 5'-AGGG TTTCATCCAGGATCGAGCAG-3' for 5' primer and 5'-ATCTTCTTCCAGATGGT GAGCGAG-3' for 3' primer. The primer set used to amplify $\beta$-actin was: 5'-ACTA CCTCATGAAGATCCTCA-3' for ' 5' primer and 5'-CAGGAGGAGCAATGATCTTGA-3' for $3^{\prime}$ primer. The cycling conditions for Bax cDNA amplification were $94^{\circ} \mathrm{C}$ for one minute, $60^{\circ} \mathrm{C}$ for one minute, and $72^{\circ} \mathrm{C}$ for two minutes for 38 cycles. The length of the RT-PCR product for Bax was $588 \mathrm{bp}$. The cycling conditions for $\beta$-actin cDNA amplification were $94^{\circ} \mathrm{C}$ for one minute, $60^{\circ} \mathrm{C}$ for one minute, and $72^{\circ} \mathrm{C}$ for two minutes for 30 cycles. Southern hybridisation was used to increase the sensitivity and specificity of detecting amplified Bax and $\beta$-actin PCR products. Briefly, aliquots $(10 \mu \mathrm{l})$ of PCR reaction mixture $(100 \mu \mathrm{l})$ were run on a $1.5 \%$ agarose gel and the separated PCR products were alkali denatured and capillary transferred onto a positively charged nylon membrane (Hybond-N+, Amersham). EcoRI fragment (800 bp) of pSKmBax containing the mouse Bax cDNA coding region (a generous gift from Dr Y Kuchino, National Cancer Centre Research Institute, Tokyo, Japan) and subcloned (pSKhbAct) human $\beta$-actin cDNA fragment (400 bp) were used as hybridisation probes after labelling with alkaline phosphatase in conjunction with chemiluminescent detection of hybridised probes with the AlkPhos DIRECT kit based on the instructions provided by the manufacturer (Amersham). Homology between mouse and human Bax cDNA was about $90 \%$ by basic BLAST search and the use of mouse Bax cDNA for hybridisation of human Bax was justified to confirm the specific binding of this probe to 588 bp human Bax PCR products and not to human Bcl-2 and Bcl-xL PCR products. Using diluted EcoRI fragment of pSKmBax and diluted $\beta$-actin cDNA fragment as templates, we then determined the sensitivity of PCR followed by Southern hybridisation. Using this method, $10^{-3} \mathrm{fg}$ (femtograms) of Bax and $\beta$-actin templates were detected as a single intense band. Compared with the single RT-PCR method with ethidium bromide (Et-Br) staining, the RT-PCR method followed by Southern hybridisation was at least 1000-fold more sensitive.

\section{REAL TIME QUANTITATIVE PCR WITH}

FLUOROGENIC PROBES

Total RNA was extracted as previously described $^{25}$ from the isolated specimen of colonic epithelium. Reverse transcription of extracted RNA (500 ng) was performed using RNase H-deficient reverse transcriptase (Superscript II, Life Technologies) and oligo(dT) primers (Life Technologies). Aliquots $(2 \mu \mathrm{l})$ of diluted RT reaction mixture $(200 \mu \mathrm{l})$ were used for quantitation of $B a x$ and glyceraldehyde-3-phosphate dehydrogenase (GAPDH) gene expression by real time PCR assay. The primer set used to amplify Bax was: 5'-TGG AGCTGCAGAGGATGATTG-3' for 5' primer and 5'GAAGTTGCCGTCAGAAAACATG- 3' for 3' primer. The primer set used to amplify GAPDH was: 5'-GAAGGTGAAGGTCGGA GTC-3' for 5' primer and 5'-GAAGATGG TGATGGGATTTC-3' for 3' primer. The FAM conjugated fluorogenic probe used to quantify Bax gene expression was: 5'-FAM-AGAGG TCTTTTTCCGAGTGGCAGCTG-3' with a sequence located between the PCR primers. The JOE conjugated fluorogenic probe used to quantify GAPDH gene expression was: 5'-JOECAAGCTTCCCGTTCTCAGCC-3' with a sequence located between the PCR primers. The fluorogenic probes were synthesised by PE Applied Biosystems (Foster City, California, USA). The PCR reaction was performed using the Taq-Man PCR kit (PE Applied Biosystems) as previously described. ${ }^{26}$ Following activation of the AmpliTaq Gold (PE Applied Biosystems) for 10 minute at $95^{\circ} \mathrm{C}, 35$ cycles of 15 seconds at $95^{\circ} \mathrm{C}$ and one minute at $62^{\circ} \mathrm{C}$ were carried out by a model 7700 Sequence Detector (PE Applied Biosystems). Real time fluorescence measurements were taken and a threshold cycle $\left(\mathrm{C}_{\mathrm{T}}\right)$ value for each sample was calculated by determining the point at which the fluorescence intensity exceeded a threshold limit (10 times the standard deviation of the baseline) by a model 7700 Sequence Detector. ${ }^{27}$ For Bax, a standard curve of the $\mathrm{C}_{\mathrm{T}}$ values obtained from serially diluted $\mathrm{pSKmBax}$ was constructed. The $\mathrm{C}_{\mathrm{T}}$ values for Bax transcripts from clinical specimens were plotted on the standard curve, and the amounts (fg) of Bax transcripts were calculated automatically by Sequence Detector version 1.6 (PE Applied Biosystems), a software package for data analysis. The amounts (fg) are shown as the amount of Bax transcripts and not as the amount of plasmid (pSKmBax). For GAPDH, a standard curve of $\mathrm{C}_{\mathrm{T}}$ values obtained from serially diluted standard samples (stocked RT reaction mixture from colonic biopsy specimens) was constructed. The $\mathrm{C}_{\mathrm{T}}$ values for GAPDH transcripts from clinical specimens were plotted on the standard curve, and the relative amounts of GAPDH transcripts to the standard sample were calculated automatically by Sequence Detector version 1.6. 
Mean $\mathrm{C}_{\mathrm{T}}$ for $\mathrm{GAPDH}$ transcripts of the standard sample was 25.6 and this value was used for standardisation of clinical specimens. Real time quantitative PCR of all samples was performed at the same time with the same 96 well plate. Each sample was tested in duplicate, and the average of the two values was used for calculation. The variability between the two values of the samples was almost zero. After standardisation, the amount of Bax transcript (fg) was expressed relative to that of GAPDH $\left(\mathrm{C}_{\mathrm{T}}=25.6\right)$. Samples were defined as negative if $\mathrm{C}_{\mathrm{T}}$ values exceeded 35 cycles. Group data were expressed as mean (SD) and differences in transcript levels between groups were analysed by Student's $t$ test. A p value less than 5\% was considered significant.

FLOW CYTOMETRIC ANALYSIS

The isolated epithelial sheets were incubated with $1000 \mathrm{U} / \mathrm{ml}$ of dispase (Godo Syusei, Tokyo) in RPMI 1640 at $37^{\circ} \mathrm{C}$ for 40 minutes. The dispersed cells were washed twice with RPMI1640 supplemented with 5\% fetal calf serum and then incubated with FITC conjugated anti-CD3 mAb (Becton Dickinson, Mountain View, California, USA) at $4^{\circ} \mathrm{C}$ for 30 minutes. Stained cells were washed twice with PBS containing $1 \%$ fetal calf serum at $4^{\circ} \mathrm{C}$, fixed with $1 \%$ paraformaldehyde in PBS, and analysed by FACScan (Becton Dickinson).

\section{Results}

IMMUNOHISTOCHEMICAL DETECTION OF Bax AND BCl-2 IN NORMAL COLONIC EPITHELIUM AND UC

In colonic epithelium samples obtained from active lesions of UC and control subjects, Bcl-2

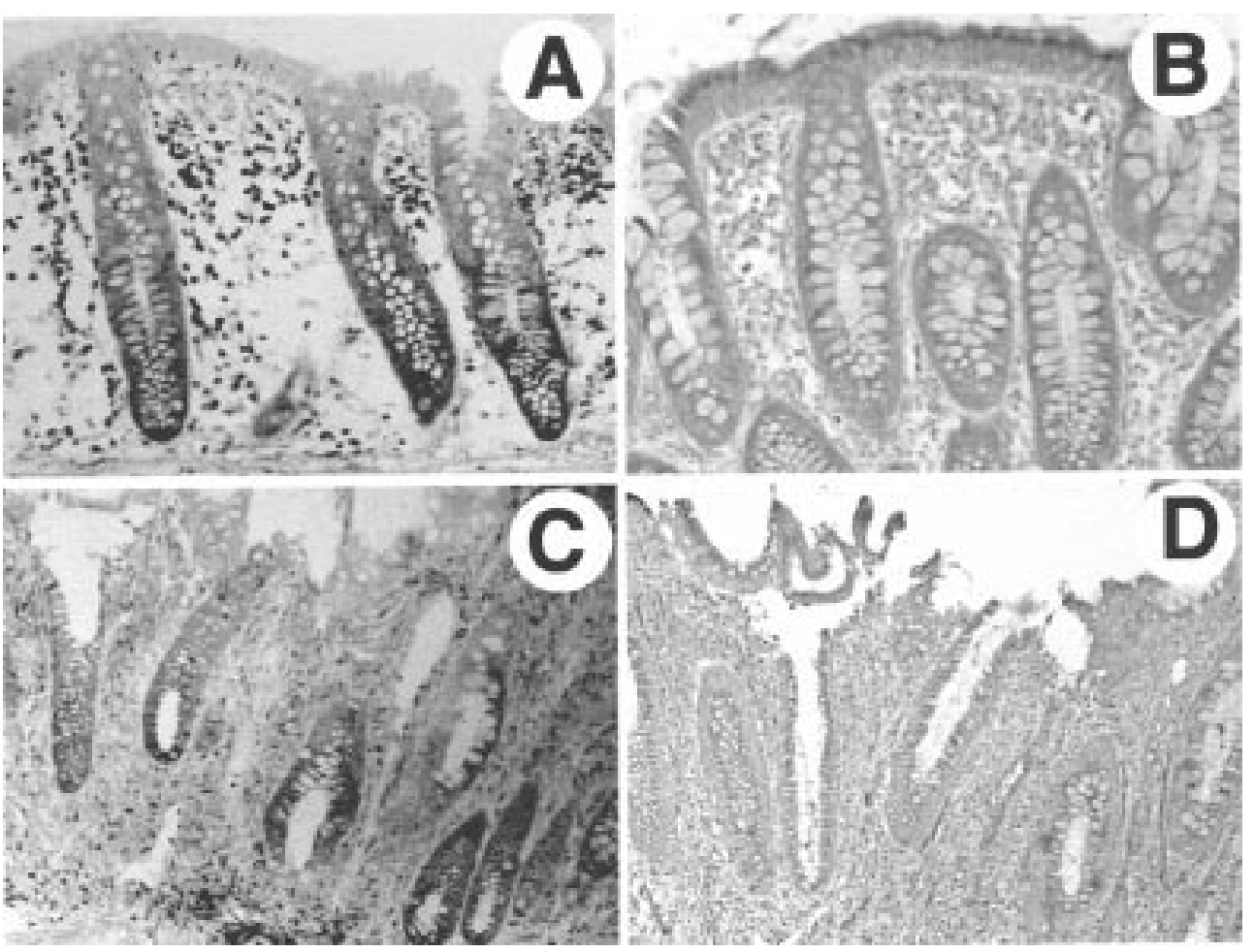

immunoreactivity was strongest in the bases of crypts while it tended to be weaker in epithelial cells that had migrated upwards towards the luminal surface. Epithelial cells on the luminal surface were almost free of $\mathrm{Bcl}-2$ staining (fig 1A, 1C). Thus the pattern and intensity of Bcl-2 immunoreactivity in colonic epithelium of active UC were not different from those of normal colonic epithelium.

In normal colonic epithelium, Bax immunoreactivity was confined to the areas of colonic epithelial cells on the luminal surface while epithelial cells in the lower two thirds of the crypts were negative for Bax (fig 1B). In actively inflamed colonic mucosa of UC, Bax immunoreactivity was obscure both in epithelial cells on the luminal surface and in epithelial cells of the whole crypts (fig 1D). However, because of the poor signal to noise ratio and high background, we were unable to confirm the absence of Bax expression in the colonic epithelium in active lesions of UC solely by immunohistochemical detection of Bax.

ISOLATION OF CRYPT AND SURFACE EPITHELIUM FROM COLONIC BIOPSY SPECIMENS

It is important to examine Bax expression at both the protein and mRNA levels using reliable methods. For this purpose, we isolated single sheets of whole crypt and surface epithelium from colonic biopsy specimens and examined them morphologically and microscopically after haematoxylin and eosin staining. Figure 2 shows representative samples of isolated whole crypt and surface epithelium from normal $(\mathrm{A}, \mathrm{B})$, active $(\mathrm{C}, \mathrm{D})$, and inactive $\mathrm{UC}(\mathrm{E}, \mathrm{F})$ colonic biopsy specimens. Photomi-

Figure 1 Immunohistochemical detection of Bcl-2 and Bax proteins in control and active ulcerative colitis (UC) colonic epithelium. Normal $(A$ and $B)$ and active UC ( $C$ and D) colonic mucosa samples were stained for Bcl-2 $(A$ and $C)$ or $B a x(B$ and D). Note expression of $B c l-2$ in the lower half of the crypt epithelium in normal $(A)$ and active UC $(C)$ colonic mucosa. Bax expression is confined to the surface epithelium in the normal colonic mucosa (B). Bax staining is obscure in colonic epithelium in active UC (D) (original magnification $\times 100$ ). 

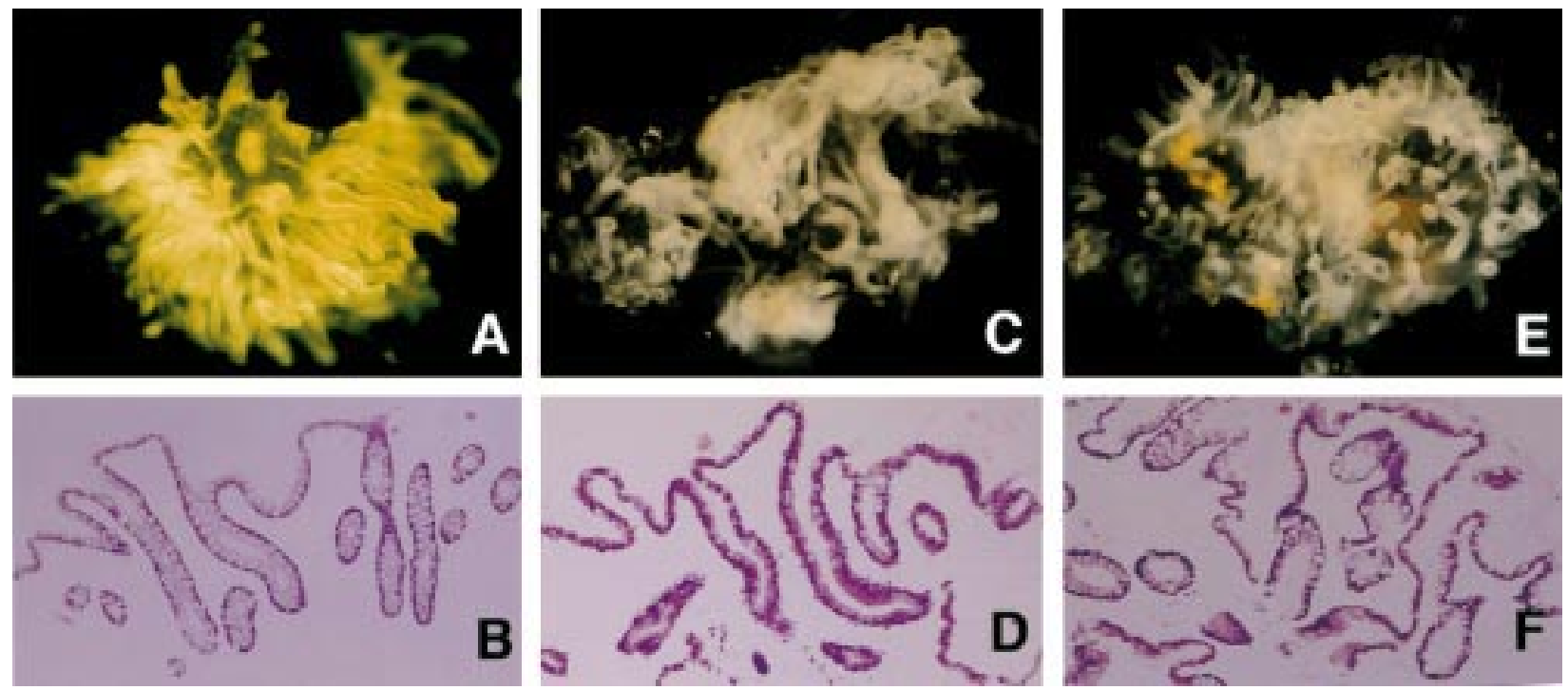

Figure 2 Isolated surface and crypt epithelium from control, active, and inactive ulcerative colitis (UC) colonic biopsy specimens. Photomicrographs of isolated sheet of colonic epithelium $(\times 20)(A, C, E)$ and histological sections of isolated colonic epithelium stained with haematoxylin and eosin (original magnification $\times 50)(B, D, F)$. The isolated epithelia from control $(A, B)$, active $(C, D)$, and inactive $U C(E, F)$ colonic biopsy specimens were free of stromal elements that surround each crypt in vivo.

crographs and histological sections showed that the isolated crypts and surface epithelia were free of non-epithelial elements in all specimens. Dispersed cells from the isolated crypts and surface epithelium were used for staining of CD3 and for flow cytometric analysis. The population of contaminated CD3 positive cells was about $3 \%$ of the isolated epithelium in all specimens (data not shown).

IMMUNOBLOT ANALYSIS OF Bax, Bcl-2, Bcl-XL, AND CD95 EXPRESSION IN COLONIC EPITHELIUM Whole cell lysates of colonic epithelium isolated from normal, active, and inactive UC colonic biopsy specimens were probed with the appropriate antibody to compare Bax, Bcl-2, $\mathrm{Bcl}-\mathrm{xL}$, and CD95 protein levels in these samples by immunoblot analysis (fig 3). No bands of Bax protein were detectable in any sample of active UC $(n=11)$ while one major band of Bax
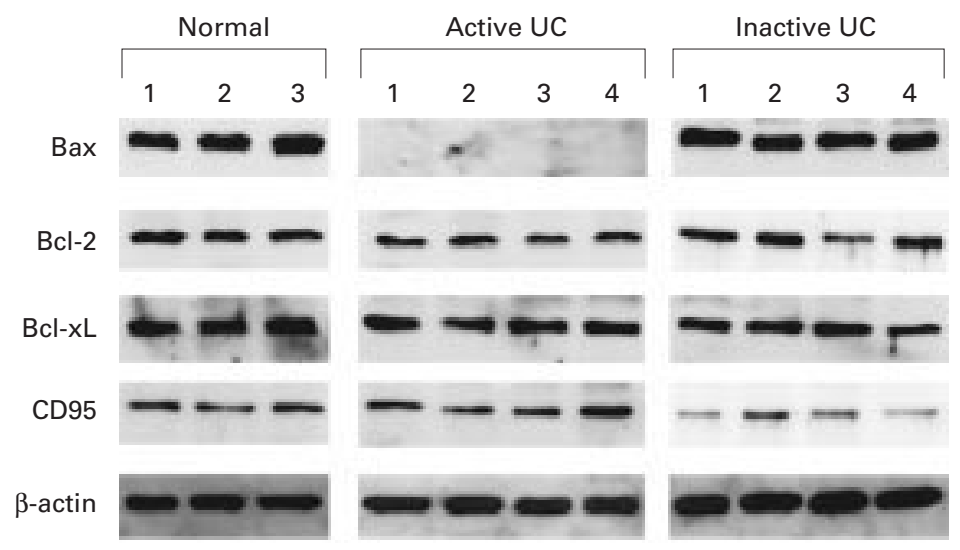

Figure 3 Detection of Bax, Bcl-2, Bcl-xL,CD95, and $\beta$-actin proteins in epithelial tissues isolated from control, active, and inactive ulcerative colitis (UC) colonic biopsy specimens by western blotting. Results are representative of duplicate experiments with similar results. Lysates were prepared from epithelium isolated from control, active, and inactive UC colonic biopsy specimens. Immunoblotting was performed using anti-Bax antibody, anti-Bcl-2 antibody, anti-Bcl-xL antibody, anti-CD95 antibody, and anti- $\beta$-actin antibody. No bands of Bax protein were evident in lysates of colonic epithelium isolated from active UC colonic biopsy specimens while one major band of Bax was observed in lysates of all samples from control and inactive UC colonic biopsy specimens. In contrast with Bax, the bands of Bcl-2, Bcl-xL, $C D 95$, and $\beta$-actin were detected in lysates of all subjects at about the same intensity. was detected in each sample of normal $(n=10)$ and inactive UC $(n=8)$. In contrast with Bax, bands of equal intensity for Bcl-2, Bcl-xL, CD95, and $\beta$-actin were detected in all cases (fig 3).

Bax mRNA LEVELS IN COLONIC EPITHELIUM OF UC AND CONTROL SUBJECTS

Bax protein expression was strongly reduced or negative in active UC but was evident in normal and inactive UC colonic epithelium (fig 3). To further confirm downregulation of Bax in active UC colonic epithelium, total RNA was extracted from colonic epithelium specimens of normal, active, and inactive UC. Bax mRNA expression was examined by RT-PCR followed by Southern hybridisation using mouse Bax cDNA as a probe. $\beta$-actin mRNA expression was examined as an internal control by RT-PCR followed by Southern hybridisation using human $\beta$-actin cDNA fragment as a probe (fig 4A, B). In four of five cases with active UC (case Nos 1, 2, 4 and 5; fig 4A), no bands of Bax transcripts were detected in extracted RNA of colonic epithelium. In the remaining case, a low intensity Bax band was identified (case No 3; fig 4A). In contrast, intense bands of Bax transcripts were detected in all seven normal and in all five inactive UC cases (fig 4A, 4B). In all samples, including those from active $U C$, intense bands of $\beta$-actin transcripts were detectable (fig 4A, B).

Downregulation of $\mathrm{Bax}$ gene expression observed in active UC was further examined by real time PCR assay. In these assays the relative amounts of Bax gene transcripts were quantified in normal $(n=6)$, inactive $(n=8)$, and active UC $(n=15)$ colonic epithelia, using GAPDH gene transcripts as internal control for standardisation (fig $4 \mathrm{C}$ ). The $\mathrm{C}_{\mathrm{T}}$ values of $\mathrm{GAPDH}$ gene transcripts of colonic epithelium in each group were 26.0 (1.1) in normal, 25.3 (1.9) in inactive UC, and 24.6 (2.3) in active UC. There were no significant differences in $\mathrm{C}_{\mathrm{T}}$ values of GAPDH gene transcripts between the 
A Normal Active UC

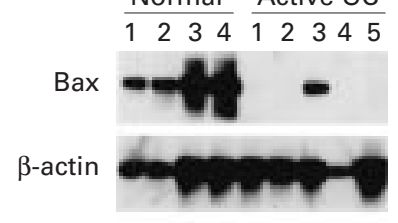

B Normal Inactive UC

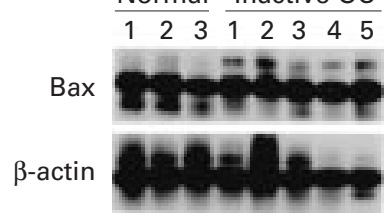

C

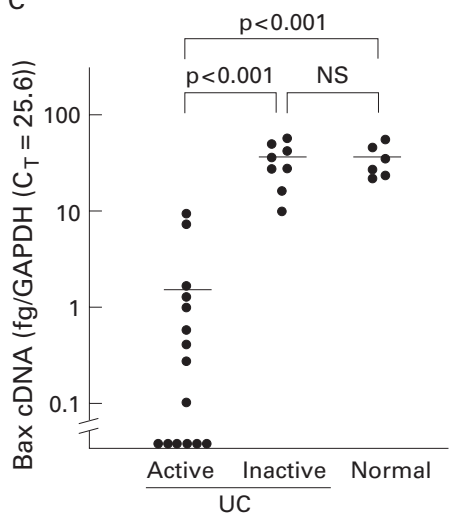

Figure $4(A, B)$ Detection of Bax $m R N A$ in colonic epithelium obtained from ulcerative colitis (UC) and control colonic biopsy specimens. Total RNA was extracted from colonic epithelium isolated from control, active, and inactive UC colonic biopsy specimens. Bax and $\beta$-actin cDNA was amplified by reverse transcription-polymerase chain (RT-PCR) and detected by Southern hybridisation using mouse Bax cDNA or human $\beta$-actin cDNA fragment as a probe. Bands of Bax transcripts were not detected or markedly reduced in extracted RNA of colonic epithelium from active UC colonic mucosa, while intense bands of Bax transcripts were observed in all samples from normal subjects and in all colonic epithelial samples isolated from inactive UC colonic mucosa. These results are representative of duplicate experiments with similar results. (C) Relative quantitation of Bax cDNA by real time PCR. Total RNA was extracted from colonic epithelium isolated from control, inactive, and active UC colonic biopsy specimens. After synthesis of cDNA by RT reaction, real time PCR was performed using the Taq-Man PCR kit as described in patients and methods. The mean threshold cycle $\left(C_{T}\right)$ value for $G A P D H$ gene transcripts of the standard sample was 25.6 and this value was used for standardisation of clinical specimens. Each sample was tested in duplicate, and the average of the two values was used for calculation. After standardisation, the amount of Bax gene transcript $(f g)$ was expressed relative to that of $G A P D H\left(C_{T}=25.6\right)$. Horizontal bars represent the mean values of each group. Results are representative of duplicate experiments with similar results.

$$
\text { (ng/ml) }
$$

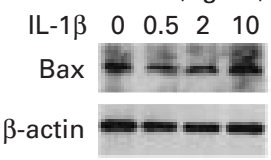

(ng/ml)

IL-6 $\quad 0 \quad 1 \quad 10100$

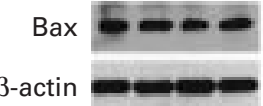

(ng/ml)

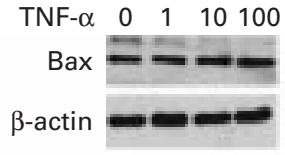

(mM)

SIN-1 01110100

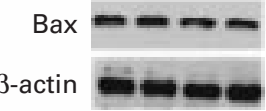

$(\mathrm{U} / \mathrm{ml})$

$\mathrm{IL}-4 \quad 0 \quad 5 \quad 50500$

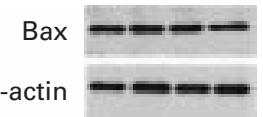

$(\mu \mathrm{g} / \mathrm{ml})$

IFN- $\gamma \quad 0 \quad 0.11110$

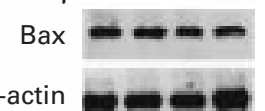

Figure 5 Immunoblot analysis of lysates of HT29 cells cultured for 24 hours with or without various inflammatory mediators. HT29 cells $\left(5 \times 10^{5}\right.$ cells) were cultured with or without interleukin (IL) $-1 \beta(0.5,2$, or $10 \mathrm{ng} / \mathrm{ml}), I L-4(5,50$, or $500 \mathrm{U} / \mathrm{ml}), I L-6(1,10$, or $100 \mathrm{ng} / \mathrm{ml})$, tumour necrosis factor a (TNF-a) $(1,10$, or $100 \mathrm{ng} / \mathrm{ml})$, interferon $\gamma$

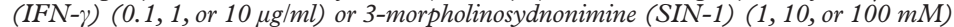
in $2 \mathrm{ml}$ of RPMI 1640 with 10\% fetal calf serum for 24 hours. Cells were harvested and whole cell lysates were obtained for comparison of protein levels of Bax and $\beta$-actin in lysates $(20 \mu \mathrm{g})$ of cultured HT29 cells by immunoblot analysis. No up or downregulation of Bax was noted under any culture condition studied. Results are from one of two experiments with similar results.

groups. The relative amounts of Bax gene transcripts (fg/GAPDH $\left.\left(\mathrm{C}_{\mathrm{T}}=25.6\right)\right)$ of colonic epithelium in each group were 32.4 (12.0) in normal, 34.4 (19.6) in inactive UC, and 1.5 (3.1) in active $\mathrm{UC}$, and the relative amount of Bax gene transcripts in active UC colonic epithelium was significantly lower than in other groups (active UC $v$ normal, $\mathrm{p}<0.001$; active UC $v$ inactive UC, $\mathrm{p}<0.001)$. These results confirmed downregulation of Bax gene expression in the colonic epithelium of active UC.

We also compared the relative amounts of Bax gene transcripts (fg/GAPDH $\left(\mathrm{C}_{\mathrm{T}}=25.6\right)$ ) in colonic epithelium of active UC with those in active Crohn's disease $(n=5)$, inactive Crohn's disease $(n=3)$, and ischaemic colitis

$(n=2)$. The relative amounts of Bax gene transcripts (fg/GAPDH $\left(\mathrm{C}_{\mathrm{T}}=25.6\right)$ ) in colonic epithelium from the latter three groups were 1.3 (1.8), 18.5 (15.6), and 3.2 (2.6), respectively. These results suggest that downregulation of Bax gene expression in the colonic epithelium is not limited to active UC but is also present in active Crohn's disease and ischaemic colitis.

EFFECTS OF INFLAMMATORY CYTOKINES AND NITRIC OXIDE ON Bax EXPRESSION IN A COLONIC EPITHELIAL CELL LINE (HT29)

Finally, we examined if downregulation of Bax in active UC colonic mucosa was mediated by inflammatory mediators. For this purpose, we examined the effects of various cytokines and $\mathrm{NO}$ on Bax expression in a colonic epithelial cell line (HT29) in vitro. HT29 cells $\left(5 \times 10^{5}\right.$ cells) were cultured with or without IL- $1 \beta(0.5$, 2 , and $10 \mathrm{ng} / \mathrm{ml}), \mathrm{IL}-4(5,50$, and $500 \mathrm{U} / \mathrm{ml})$, IL-6 $(1,10$, and $100 \mathrm{ng} / \mathrm{ml})$, TNF- $\alpha(1,10$, and $100 \mathrm{ng} / \mathrm{ml}), \operatorname{IFN}-\gamma(0.1,1$, and $10 \mu \mathrm{g} / \mathrm{ml})$, or SIN-1 $(1,10$, and $100 \mathrm{mM})$ in $2 \mathrm{ml}$ of RPMI 1640 containing $10 \%$ fetal calf serum for 12 , 24 , or 48 hours. Cells were harvested and whole cell lysates were obtained at 12, 24, and 48 hours of culture. Bax and $\beta$-actin protein levels in lysates $(20 \mu \mathrm{g})$ of cells cultured with or without various inflammatory mediators were determined by immunoblot analysis. We could not detect up or downregulation of Bax under any condition or culture period studied (fig 5 and data not shown).

\section{Discussion}

We have recently documented the abundant presence of apoptotic colonic epithelial cells in active UC by flow cytometric analysis and demonstrated that apoptosis of these cells was unlikely to be induced by the CD95/CD95L system (Iimura et al., unpublished results). Thus cell death mechanisms other than the CD95-CD95L system contribute to induction of apoptosis of colonic epithelial cells in active UC.

In UC there is increased NO synthesis and overexpression of inducible nitric oxide synthase in inflamed colonic mucosa. ${ }^{28-30} \mathrm{NO}$ causes oxidative damage and deamination of DNA, ${ }^{31} 32$ which probably results in upregulation of p53. ${ }^{33}$ Furthermore, immunohistochemical studies have demonstrated overexpression of p53 in areas of acute inflammation in UC. ${ }^{34}$ p53 is a transcriptional modulator of Bax gene which promotes apoptosis, ${ }^{20}$ and a p53 negative response element has been identified in the $\mathrm{Bcl}-2$ gene. ${ }^{35}$ Based on these findings we postulated that Bax induced apoptosis could be operative in inflamed colonic mucosa in UC. However, unexpectedly, we found a marked reduction in Bax expression at the protein and mRNA levels in the colonic epithelium of active UC.

It is possible that any loss of surface epithelial cells in active UC samples would reduce Bax protein and Bax transcripts in each preparation and consequently affect the results of immunoblot analysis and RT-PCR. However, we confirmed the existence of surface epithelium in active UC samples in each preparation 
by morphological examination under the microscope and by haematoxylin and eosin staining of histological sections (fig 2). Previous immunohistochemical studies have shown similar expression of CD95 protein in the epithelium of normal and active UC. ${ }^{4}$ These results were also demonstrated in our study by immunoblotting; almost identical levels of CD95 protein were present in colonic epithelia of active UC and control specimens (fig 3). In addition, there were no differences in the expression levels of $\mathrm{Bcl}-2, \mathrm{Bcl}-\mathrm{xL}$, and $\beta$-actin proteins between normal, inactive, and active UC colonic epithelia by immunoblotting (fig 3). Thus loss of surface epithelial cells in active UC samples is unlikely to have affected the results of Bax immunoblotting and RT-PCR.

In the normal colon of mice, Krajewski and colleagues $^{18}$ showed more intense Bax immunostaining in surface epithelial cells than in the bases of the crypts, whereas Bcl-2 immunostaining was stronger in epithelial cells located in the bases of the crypts. In the present study, a reciprocal pattern of $\mathrm{Bax}$ and $\mathrm{Bcl}-2$ expression in normal human colonic epithelium was observed immunohistochemically (fig $1 \mathrm{~A}, \mathrm{~B})$. In the normal colonic epithelium, columnar epithelial cells proliferate in the bottom of the crypts, migrate upwards along the crypts, and slough off at the luminal surface. ${ }^{36-38}$ Furthermore, surface epithelial cells are thought to undergo apoptosis prior to sloughing as many apoptotic bodies have been observed in these areas. ${ }^{39}$ Because of the increased Bax to Bcl-2 protein ratio in normal colonic surface epithelium, it is conceivable to hypothesise that Bax may act as an inducer of apoptosis in surface epithelial cells. Thus Bax expression may be the consequence of the final differentiation of colonic epithelial cells and a reduction of its expression in colonic epithelial cells of active UC may reflect disordered differentiation of colonic epithelial cells in inflamed colonic mucosa of UC.

However, we also observed reduced expression of Bax in colonic epithelium of active Crohn's disease $(n=5)$ and in non-IBD inflammatory controls (ischaemic colitis; $n=2$ ) by real time PCR assay, although the number of patients examined was very small. Thus reduced expression of Bax in inflamed colonic epithelium appeared not to be a primary event in UC but a secondary event related to the local inflammatory process. These results advance the hypothesis that Bax expression may be regulated by inflammatory mediators.

Previous studies have shown that colonic epithelial cells of active UC contain activated nuclear factor $\kappa \mathrm{B}(\mathrm{NF}-\kappa \mathrm{B})$ which is an important regulator of proinflammatory cytokines and inhibitor of apoptosis. ${ }^{41}{ }^{42}$ This implies inflammatory cytokine involvement not only in inflammation associated with cell death but also in activation of cellular protection. For example, mucosal protective IL-1 receptor antagonist isoforms have been shown to be upregulated in native inflamed intestinal epithelial cells. ${ }^{43}$ Taken together, these findings suggest that $\mathrm{NF}-\kappa \mathrm{B}$ induced proteins may downregulate Bax gene expression in inflamed surface epithelial cells. Indeed, IL-6, the receptor of which is expressed on colonic epithelial cells, ${ }^{9}$ was reported to downregulate Bax gene expression in myeloid leukaemic cells. ${ }^{44}$ To determine if Bax downregulation in active UC colonic epithelium is secondary to the inflammatory process, we examined the effects of various inflammatory mediators (IL- $1 \beta$, IL-4, IL-6, TNF- $\alpha$, IFN- $\gamma$, and NO) on Bax expression of a colonic epithelial cell line (HT29) in vitro. Under all conditions studied we could not observe up or downregulation of Bax by any of the above mediators (fig 5). However, HT29 is a colon cancer cell line and thus may not reflect regulation of Bax expression in vivo. It is possible that Bax downregulation in colonic epithelium may be mediated by other mediators or by a combination of inflammatory mediators. Further studies are necessary to examine the mechanisms of Bax downregulation in inflamed colonic epithelium in UC.

In conclusion, we have demonstrated in the present study low expression of Bax both at the protein and mRNA levels in inflamed colonic epithelium of UC. Furthermore, apoptosis mediated by the $\mathrm{Bax} / \mathrm{Bcl}-2$ system was not operational in inflamed colonic epithelium in UC.

This work was supported in part by Sato Memorial Cancer Research Fund and Grant-in-Aid for Scientific Research (C). We thank Dr Kuchino for the generous gift of pSKmBax. We thank Dr Matsushita for the technical advice on colonic epitheial isolation and immunohistochemistry. 1 Taylor CT, Dzus AL, Colgan SP. Autocrine regulation of epithelial permeability by hypoxia: role for polarized release 68 .

2 Schmitz H, Barmeyer C, Fromm M, et al. Altered tight junction structure contributes to the impaired epithelial barrier function in ulcerative colitis. Gastroenterology 1999; 116:301-9.

3 Hond ED, Hiele M, Evenepoel P, et al. In vivo butyrate metabolism and colonic permeability in extensive ulcerative colitis. Gastroenterology 1998;115:584-90.

4 Strater J, Wellisch I, Riedl S, et al. CD95 (APO-1/Fas)mediated apoptosis in colon epithelial cells: A possible role in ulcerative colitis. Gastroenterology 1997;113:160-7.

5 Ueyama H, Kiyohara T, Sawada N, et al. High Fas ligand expression on lymphocytes in lesions of ulcerative colitis. Gut 1998;43:48-55.

6 Lowin B, Hahne M, Mattmann C, et al. Cytolytic T-cell cytotoxicity is mediated through perforin and Fas lytic cytotoxicity is mediated through
pathways. Nature 1994;370:650-2.

7 Laster SM, Wood JG, Gooding LR. Tumor necrosis factor can induce both apoptotic and necrotic forms of cell. $\mathcal{F}$ Immunol 1988;141:221-7.

8 Mesmer UK, Reed JC, Brune B. Bcl-2 protects macrophages from nitric oxide-induced apoptosis. I Biol Chem 1996;271:20192-7.

9 Panja A, Goldberg S, Eckmann L, et al. The regulation and functional consequence of proinflammatory cytokine binding on human intestinal epithelial cells. F Immunol 1998;161:3675-84.

10 Jacobson MD, Weil M, Raff MC. Programmed cell death in animal development. Cell 1997;88:347-54.

11 Reed JC. Bcl-2 and the regulation of programmed cell death. F Cell Biol 1994;124:1-6.

12 Korsmyer SJ. Bcl-2 initiates a new category of oncogenes: Korsmyer SJ. Bcl-2 initiates a new category of
regulators of cell death. Blood 1992;80:879-86.

13 Boise LH, Garcia-G M, Postema CE, et al. Bcl-X, a bcl-2-related gene that functions as a dominant regulator of apoptotic cell death. Cell 1993;74:597-608.

14 Oltvai ZN, Milliman CL, Korsmeyer SJ. Bcl-2 heterodimerizes in vivo with a conserved homolog, Bax, that accelerates programmed cell death. Cell 1993;74:609-19.

15 Rosse T, Olivier R, Monney L, et al. Bcl-2 prolongs cell survival after Bax-induced release of cytochrome c. Nature 1998;391:496-9.

16 Gross A, Jockel J, Wei MC, et al. Enforced dimerization of BAX results in its translocation, mitochondrial dysfunction and apoptosis. EMBO $\mathcal{F} 1998 ; 17: 3878-85$.

17 Pastorino JG, Chen ST, Tafani M, et al. The overexpression of Bax produces cell death upon induction of the of Bax produces cell death upon induction of the
mitochondrial permeability transition. $f$ Biol Chem 1998; 273:7770-5. 
18 Krajewski S, Krajewski M, Shabaik A, et al. Immunohistochemical determination of in vivo distribution of $\mathrm{Bax}$, a

19 Potten CS. The significance of spontaneous and induced apoptosis in the gastrointestinal tract of mice. Cancer Metastasis Rev 1992;11:179-95.

20 Miyashita T, Krajewska S, Wang HG, et al. Tumor suppressor p53 is a regulator of bcl-2 and bax gene expression in vitro and in vivo. Oncogene 1994;9:1799-805.

21 Selvakumaran M, Lin HK, Miyashita T, et al. Immediate early up-regulation of bax expression by p 53 but not TGF $\beta 1$ : a paradigm for distinct apoptotic pathways. Oncogene 1994;9:1791-8.

22 Garland CF, Lilienfeld AM, Mendeloff AI, et al. Incidence rates of ulcerative colitis and Crohn's disease in 15 areas of the United States. Gastroenterology 1981;81:1115-24.

23 Matts F. The value of rectal biopsy in the diagnosis of ulcerative colitis. $Q 7 M$ 1961;30:393-407.

24 Matsubara Y, Ichinose M, Yahagi N, et al. Hepatocyte growth factor activator: a possible regulator of morphogengrowth factor activator: a possible regulator of morphogenesis during development of the rat gastrointes
Biochem Biophys Res Commun 1998;253:477-84.

25 Chomczynski P, Sacchi N. Single-step method of RNA isolation by acid guanidinium thiocyanate-phenol-chloroform extraction. Anal Biochem 1987;162:156-9.

26 Kimura H, Morita M, Yabuta Y, et al. Quantitative analysis of Epstein-Barr virus load by using a real-time PCR assay. f Clin Microbiol 1999;37:132-6.

27 Heid CA, Stevens J, Livak KJ, et al. Real time quantitative PCR. Genome Res 1996;6:986-94.

28 Middleton SJ, Shorthouse M, Hunter JO. Increased nitric oxide synthesis in ulcerative colitis. Lancet 1993;341:465-6.

29 Lundberg JON, Hellstrom PM, Lundberg JM. Greatly increased luminal nitric oxide in ulcerative colitis. Lancet 1994;344:1673-4.

30 Smith NKB, Evans SM, Hawkey CJ, et al. Nitric oxide synthase activity in ulcerative colitis and Crohn's disease. Lancet 1993;342:338-40.

31 Wink DA, Kasprzak KS, Maragos CM, et al. DNAdeaminating ability and genotoxicity of nitric oxide and its deaminating ability and genotoxicity of
progenitors. Science 1991;254:1001-3.
32 Nguyen T, Brunson D, Crespi CL, et al. DNA damage and mutation in human cells exposed to nitric oxide in vitro. Proc Natl Acad Sci USA 1992;89:3030-4.

33 Mesmer UK, Ankarkrona M, Nicotera P, et al. p53 expression in nitric oxide-induced apoptosis. FEBS Lett 1994; 355:23-6.

34 Krishna M, Woda B, Savas L, et al. Expression of p53 antigen in inflamed and regenerated mucosa in ulcerative colitis and Crohn's disease. Modern Pathol 1995;8:654-7.

35 Miyashita T, Harigai M, Hanada M, et al. Identification of a p53-dependent negative response element in the bcl-2 gene. Cancer Res 1994;54:3131-5.

36 Gibson PR, Pol EVD, Barratt PJ, et al. Ulcerative colitis-a disease characterised by the abnormal colonic epithelial cell? Gut 1988;29:516-21.

37 Allan A, Bristol JB, Williamson RCN. Crypt cell production rate in ulcerative colitis: differential increments in remission and relapse. Gut 1985;26:999-1003.

38 Serafini EP, Kirk AP, Chamber TJ. Rate and pattern of epithelial cell proliferation in ulcerative colitis. Gut 1981;22: $648-52$.

39 Lee FD. Importance of apoptosis in the histopathology of drug related lesions in the large intestine. $\mathcal{f}$ Clin Pathol 1993;46:118-22.

40 Iwanaga T, Han H, Fujita T. Macrophage possibly involved in the disposal of apoptotic epithelial cells in the monkey small and large intestine. Acta Med Biol 1992;40:105-13.

41 Rogler G, Brand K, Vogl D, et al. Nuclear factor $\kappa \mathrm{B}$ is activated in macrophages and epithelial cells of inflamed intestinal mucosa. Gastroenterology 1998;115:357-69.

42 Barinaga M. Apoptosis-life-death balance within the cell. Science 1996;274:724.

43 Bocker U, Damiao A, Holt L, et al. Differential expression of interleukin 1 receptor antagonist isoforms in human intestinal epithelial cells. Gastroenterology 1998;115:1426-38.

44 Lotem J, Sachs L. Regulation of bcl-2, bcl-XL and bax in the control of apoptosis by hematopoietic cytokines and dexamethasone. Cell Growth Differ 1995;6:647-53. 